\title{
ANÁlISE PEDAGÓgICA DE FILMES: GÊNERO DE ANIMAÇÃO NO ENSINO DE CIÊNCIAS
}

\author{
José Nunes dos Santos ${ }^{1}$, Maria José Fontana Gebara ${ }^{2}$ \\ Universidade Estadual de Campinas - UNICAMP, Campinas - SP. Universidade Federal de São Carlos - UFSCar, São \\ Carlos-SP.E- mail: nunesvi@hotmail.com, maria.gebara@ufscar.br
}

\begin{abstract}
RESUMO
A escolha de filmes para abordar conteúdos escolares implica a desconstrução, a identificação e a discriminação dos elementos que compõem o seu conjunto e a articulação com o tema trabalhado. Realizamos uma pesquisa com o propósito de responder à seguinte questão: há trechos do enredo fílmico que podem ser destacados para melhor estimular o interesse do alunado na construção de conceitos científicos? Neste artigo, analisamos dois filmes do gênero de animação, "Vida de Inseto" e "Bee Movie", com o objetivo de identificar trechos do enredo que facilitem a apropriação de conceitos científicos de Ecologia. O trabalho teve natureza qualitativa, ancorada da análise de imagens e enredo que compõem os filmes. Nos filmes, a música e o enredo possibilitam a construção do conhecimento científico. Entretanto, a ficção científica lida com um mundo imaginário, que pode contrariar a realidade, e os filmes apresentam algumas falhas conceituais científicos do ponto de vista biológico.

Palavras-chave: Filme de animação. Ensino de Ciências. Conceitos científicos. Recurso didático. Construção do conhecimento
\end{abstract}

\section{EDUCATIONAL FILM REVIEW: GENDER OF ANIMATION IN TEACHING SCIENCE}

\section{ABSTRACT}

The choice of films to approach school contents implicate the deconstruction, identification and discrimination of the elements that make up your set and the articulation with the theme worked. We conducted a survey to answer the following question: there are passages of the filmic plot that can be deployed to better stimulate the interest of students in the construction of scientific concepts? In this article, we examined two animated films of the genre, "A bug's life" and "Bee Movie", with the objective of identifying passages of the plot which facilitate the appropriation of scientific concepts of Ecology. The study was qualitative in nature, anchored the analysis of images and films that make up the plot. In the movies, the music and the plot makes it possible for the construction of scientific knowledge. However, science fiction deals with an imaginary world, which can counteract the reality, and the films feature some scientific conceptual flaws of the biological point of view.

Keywords: Animated film. Teaching science. Scientific concepts. Educational resource. Knowledge construction. 


\section{INTRODUÇÃO}

Entendendo a escola como o ambiente mais adequado para a obtenção do saber científico por meio da estimulação das capacidades intelectuais dos alunos, acreditamos ser o professor, como mediador desse processo, o principal ator. Por outro lado, percebemos que há um grande incômodo por parte dos professores de Ciências Naturais da educação básica, na busca de recursos pedagógicos que facilitem a aprendizagem.

Verificamos que essas angústias e inquietações estão presentes, cotidianamente, em ambientes de trabalho, e são vivenciadas pela maior parte dos professores de Ciências com os quais convivemos. Para superá-las, é preciso, entre outras coisas, considerar a Ciência como processo de construção humana, histórica e em transformação, entendendo que é necessário pensar e repensar as práticas pedagógicas, mudar metodologias e buscar recursos que despertem o interesse do aluno durante o processo de apropriação do conhecimento escolar.

O papel que a escola ocupa hoje na sociedade brasileira é complexo e o "fazer" docente enfrenta muitos obstáculos, como, planejar aulas que contemplem os conteúdos previstos, para série e para o período, de modo contextualizado e significativo, organizando atividades e utilizando recursos pedagógicos disponíveis na escola.

Dentre os recursos disponíveis, Almeida (apud NAPOLITANO, 2010, p. 12) afirma que a utilização do cinema na educação "é importante porque traz para a escola aquilo que ela se nega a ser e que poderia transformá-la em algo vivido e fundamental", viabilizando atividades que vão além da rotina e são ferramentas indispensáveis, uma vez que contribuem significativamente para a aprendizagem dos alunos.

Ao entendermos 0 ato de ensinar como uma ação mediadora do professor que deve facilitar a construção/apropriação do conhecimento, o cinema se torna um recurso pedagógico que permite ao aluno a apropriação de conhecimentos científicos de forma lúdica, capaz de propiciar situações de troca que permitem estabelecer as relações entre o estudo do científico e a realidade.

Assim, este artigo constitui-se de uma breve análise de filmes de animação e tem como objetivo identificar trechos do enredo que facilitem a apropriação de conceitos científicos de Ecologia.

\section{METODOLOGIA}

Para a realização desta pesquisa foram selecionados dois filmes do gênero de animação "Vida de Inseto" e "Bee Movie", 
com a finalidade de promover reflexões acerca da relevância e das contribuições ao processo de elaboração do planejamento nas organizações de ensino. Desta forma, a prática da utilização de filmes em sala de aula deve estar alicerçada no planejamento de ensino.

O trabalho teve natureza qualitativa, já que, buscou levantar maiores saberes sobre as representações das cenas (o que contam e representam as personagens); ideias principais do filme: articulação com o currículo escolar (conteúdo estruturante, conteúdo básico e conteúdo específico); adequação do conteúdo relacionado ao filme; valores e conceitos científicos errados passados pelo filme; prática no cotidiano: vida do aluno, contextualização. A investigação qualitativa em educação possibilita analisar uma situação natural, coletar dados descritivos e analisar a realidade de forma contextualizada (LÜDKE; ANDRÉ, 1986).

Sendo assim, realizamos uma pesquisa com o propósito de responder à seguinte questão: há trechos do enredo fílmico que podem ser destacados e descritos para melhor estimular o interesse do alunado na construção e apropriação de conceitos científicos?

$\mathrm{Na}$ busca de respostas para esse questionamento foram descritos fragmentos do enredo fílmico e apresentados como recursos pedagógicos, por apresentarem possibilidades na sistematização de procedimentos metodológicos no ensino de Ecologia.

\section{DISCUSSÃO}

A escolha de um filme para abordar determinado conteúdo escolar implica, portanto, a desconstrução, identificação e discriminação dos elementos que compõem o seu conjunto e a articulação com o tema trabalhado em sala de aula.

Nesses termos,

Analisar um filme ou um fragmento é, antes de mais nada, no sentido científico do termo, [...] decompô-lo em seus elementos constitutivos. É despedaçar, descosturar, desunir, extrair, separar, destacar e denominar materiais que não se percebem isoladamente "a olho nu", pois se é tomado pela totalidade. Parte-se, portanto, do texto fílmico para "desconstruí-lo" e obter um conjunto de elementos distintos do próprio filme. [...] em seguida, em estabelecer elos entre esses elementos isolados, em compreender como eles se associam e se tornam cúmplices para fazer surgir um todo significante: reconstruir o filme ou o fragmento (VANOYE; GOLIOT-LÉTÉ, 1994, p. 15). 
Nesta proposta metodológica, o importante é, a partir da análise do filme, observar os elementos essenciais que podem ser destacados e descritos para melhor estimular o interesse do alunado.

O filme pode ser utilizado na sala de aula como uma forma de interagir com o conteúdo programado no plano de trabalho docente (planejamento). Ele se constitui como um recurso pedagógico que possibilita mobilizar a atenção dos alunos para a apropriação do conhecimento escolar.

\section{Vida de Inseto}

O filme "Vida de Inseto" é uma animação da Disney e da Pixar, com duração de uma hora e quarenta e dois minutos, direção de John Lasseter, com a participação de Andrew Stanton. No filme, destacam-se os temas relacionados ao comportamento e à organização de insetos (formigueiro) que vivem em sociedade, bem como, uma situação de abuso de poder, representada por Hooper, chefe de um grupo de gafanhotos.

O filme "Vida de Inseto" pode ser assistido tanto por estudantes do ensino fundamental quanto do médio para abordar temas de Ecologia e de vida em equipe. Ele permite que o professor explore, por exemplo, as relações ecológicas do mundo dos insetos, sua participação na cadeia alimentar, ecossistemas, biomas e inter- relações entre os seres vivos e seus ambientes físicos.

Ao retratar a vida de insetos, especificamente de um formigueiro, o enredo apresenta a formiga rainha no comando, coordenando uma sociedade. No entanto, fazendo uma analogia com seres humanos, o enredo do filme mostra que a liderança nem sempre é positiva, existem pessoas que podem liderar um grupo para o fracasso. Nesse caso, em certos momentos, a formiga Flick (não é a rainha), assume-se como líder, desenvolvendo ações que levam o formigueiro ao fracasso e ao sucesso.

$\mathrm{Na}$ perspectiva do espírito de liderança, o filme retrata a organização da vida das formigas, animais invertebrados que fazem parte da classe insecta, da ordem hymenoptera, e que vivem em sociedade. Além da representação de espírito de liderança entre as espécies de formigas, o filme também salienta a vida de outros representantes de insetos, como, borboletas, gafanhotos, moscas, joaninhas, que não são coordenados pelo espírito de liderança, isto é, não possuem rainhas.

Os conceitos básicos de Ecologia que fundamentam o filme são: população biológica, comunidade biológica, ecossistema, nicho ecológico, habitat, relações ecológicas, etc. O filme também possibilita discutir o funcionamento de um ecossistema que resulta da interação entre 
seus componentes bióticos (seres vivos) e seus componentes abióticos (fatores físicos e químicos).

A Ecologia é uma Ciência que vem ganhando importância na educação escolar, principalmente para o ensino de Biologia e Ciências, em razão do seu caráter interdisciplinar e multidisciplinar, que envolve outras áreas de estudos, como, a Geografia, a Química e a Física, a Economia e as Ciências Sociais. Estudar conceitos de Ecologia permite compreender alguns processos que possibilitam a vida no planeta Terra, a saber, o clima, a chuva, a qualidade do solo, os fatores ambientais, a atividade humana, os vegetais, os animais, entre outros.

Nesse sentido, a narrativa do filme possibilita abordar diferentes tópicos ecológicos em que o ambiente pode ser entendido como entorno de cada ser vivo, formado por tudo aquilo que o rodeia e o afeta (condições físico-químicas que compreendem componentes abióticos). Assim, além de problematizar o espírito de liderança entre pessoas, o filme também permite entender a interação ou atuação dos organismos com seu meio físico e biológico.

O mundo dos insetos é o grupo mais diversificado do filo Arthropoda. Os insetos são animais com plano corpóreo distinto, formado por cabeça; tórax e abdômen; três pares de pernas torácicas; um par de antenas; um sistema de trocas gasosas com o ar, composto por traqueias e espiráculos e túbulos de Malpighi como sistema excretor (AMABIS; MARTHO, 2010). A classe Insecta se encontra dentro da Superclasse Hexapoda (hexa corresponde a seis, e poda, a pernas). Cada representante tem seis pernas, por isso é chamado de hexápode, assim como as classes Collembola, Protura, Diplura, cujos integrantes possuem três pares de patas, mas não são insetos. Isto é, todo inseto é um Hexápode, mas nem todo hexápode é um inseto (AMABIS; MARTHO, 2010).

Embora o nome do filme seja "Vida de inseto", animais de diversos grupos aparecem na trama, como os irmãos tatubola (tatuzinhos-de-jardim), representantes dos crustáceos, e a aranha viúva-negra, um aracnídeo (animais peçonhentos). A maioria das personagens pertence ao subfilo hexapoda (insetos), e o filme os retrata com dois pares de pernas, quando, na realidade, um inseto possui três pares de pernas. É preciso que o professor observe eventuais inconsistências entre Ciência e ficção para que o aluno não se aproprie de conceitos errados.

\section{Bee Movie: A História de uma Abelha}

O filme "Bee Movie" é uma animação produzida pela Dream Works SKG, com duração de noventa e um minutos. O roteiro foi elaborado por Jerry Seinfeld, Spike 
Feresten, Barry Marder e Andy Robin, com direção de Steve Hickner e Simon J. Smith e a trilha sonora, composta por Rupert GregsonWilliams. Trata-se de uma história que apresenta uma classe de insetos - as abelhas - e sua complexa organização social na colmeia.

O Filme "Bee Movie" permite a complementação ao material didático, pois seu enredo aborda como tema central o "desequilíbrio ecológico". Na verdade, são consideráveis as possibilidades de temas que o filme suscita com relação aos conteúdos do ensino de Ciências, e citamos, a título de exemplo, as relações ecológicas intraespecíficas e interespecíficas (ao enfatizar as relações harmônicas e desarmônicas entre as espécies), a polinização, o nicho ecológico, o desequilíbrio ecológico, as ameaças de espécies, a organização dos insetos sociais, a preservação ambiental, entre outros temas.

O filme também permite discutir a morfologia das flores (destacar as diferentes formas, tamanhos e cores das flores e plantas), a importância da polinização para a formação de frutos e reprodução das plantas que sustentam e mantêm diferentes espécies no ecossistema.

A animação apresenta várias cenas em que ocorre a polinização, por exemplo, quando as abelhas coletoras de pólen que tinham bastante pelos e, quando visitavam as flores, um pouco de pólen ficava fixado em seus pelos, sendo transportado de uma flor à outra.

Nesse momento, o professor pode: discutir o aparelho reprodutor das plantas "flor" e observar a existência do pólen; identificar também como se processa o fenômeno da polinização, enfatizando que não são apenas as abelhas que o fazem; comparar o que o enredo fílmico mostra e salientar outros agentes de polinização, como, insetos (entomofilia), aves (ornitofilia), morcegos (quiropterofilia) e vento (anemofilia).

Ao nos ampararmos no enredo, podemos destacar a importância da divisão de tarefas na colmeia, bem como, o impacto devido à interrupção da produção de mel, fato que desencadeou um desequilíbrio ecológico entre as espécies dependentes da produção de flores. Nesse caso, podemos destacar com detalhes as consequências do desequilíbrio ecológico provocado pelas abelhas.

As relações ecológicas se constituem das interações que os indivíduos de uma espécie mantêm, tanto com indivíduos da mesma espécie quanto de outras espécies. Dessa forma, o alunado consegue perceber as relações ecológicas que podem ocorrer entre indivíduos da mesma espécie, denominadas intraespecíficas, ou entre espécies diferentes, recebendo o nome de 
interespecíficas. Algumas relações promovem benefícios às duas partes envolvidas, outras, são benéficas para uma parte, mas indiferentes ou neutras para a outra. Nesses casos, as relações são harmônicas, como a organização social das abelhas, em que a divisão de trabalho beneficia toda a colmeia. Já, de acordo com a relação desarmônica, o beneficio de um indivíduo significa, necessariamente, o prejuízo de outro.

As abelhas vivem em sociedade, com divisão de tarefas entre a rainha, o zangão e as operárias. No interior de uma colmeia, podem habitar entre 50 e 100 mil indivíduos. A rainha é uma fêmea diplóide (2n), que recebe alimentação diferenciada das outras larvas, por isso é fértil, sua função é a reprodução, originando novos indivíduos para a colmeia. As operárias são fêmeas diplóides, inférteis (outras larvas) e têm várias funções. As abelhas destinadas a serem operárias são alimentadas com mel e pólen, enquanto a larva destinada a ser rainha é alimentada com geleia real, que é a secreção glandular das operárias. As operárias também trabalham na produção dos favos e do mel, limpam e guardam a colmeia, buscam néctar e pólen nas flores.

Lembramos, contudo, que a ficção científica lida com um mundo imaginário, que pode contrariar a realidade, e os filmes podem apresentar uma visão incorreta do ponto de vista biológico. É o caso, por exemplo, do personagem Barry, representado no filme como filho de abelhas operárias, quando, na realidade, em uma colmeia, somente a rainha pode reproduzir. Outro caso é o do personagem Adam, que picou o advogado e não morreu; no mundo real, a abelha morre ao picar alguém. Isso ocorre porque o ferrão é um prolongamento do abdômen, que se rompe no momento em que $a$ abelha abandona a vítima. No filme, essa situação não acontece. Tais questões devem ser observadas durante as discussões realizadas com os alunos, mas destacamos que tais questões não invalidam as possibilidades de o filme despertar o interesse dos estudantes para o aprendizado de fenômenos científicos.

\section{CONSIDERAÇOES FINAIS}

No filme de animação "Vida de Inseto" e "Bee Movie", podemos encontrar a música e o enredo, entre outros elementos, de forma que, além do resultado visual, proporcionado pelo trabalho artístico do animador, a natureza dos elementos fílmicos pode colaborar para a construção de significados que visam à apropriação do conhecimento científico por parte dos alunos.

Para D’elia (1996, p. 163), “O cinema de animação integra elementos de todas as outras formas de expressão. É plástico, 
musical, narrativo, cinematográfico e coreográfico. Empresta das outras artes seus códigos e elementos". Ou seja, o cinema de animação é considerado arte industrial, pois se vale de instrumentos diversos para criar meios de transmitir sentimentos e emoções, integrando outras formas de expressão.

No entanto, alertamos: é importante que o professor assista a esses filmes com a intenção de verificar conceitos científicos presentes no enredo, uma vez que estes podem apresentar algumas falhas conceituais, presentes, comumentemente, nos gêneros de ficção e de animação.

Lembramos que o autor, ao criar o roteiro fílmico de animação e ficção, não está desenvolvendo um filme de gênero pedagógico, portanto, tem a liberdade de não se ater à realidade científica.

\section{REFERÊNCIAS}

AMABIS, José $M$; MARTHO, Gilberto $R$. Biologia dos organismos. 3. ed. São Paulo: Moderna, 2010.

BEE movie: a história de uma abelha. Direção: Steve Hickner, Simon J. Smith. Roteiro: Jerry Seinfeld e outros. Estados Unidos: DreamWorks SKG e DreamWorks Animation, 2007. 1 DVD.

D’ÉLIA, Céu. Animação, técnica e expressão. In: FALCÃO, Antônio Rebouças et al. Coletânea lições com cinema: animação. São Paulo: FDE, Diretoria de Projetos Especiais/Diretoria Técnica, 1996.
LÜDKE, M.; ANDRÉ, M. Pesquisa em educação: abordagens qualitativas. São Paulo: EPU, 1986.

NAPOLITANO, Marcos. Como usar o cinema na sala de aula. São Paulo: Contexto, 2010.

VANOYE, Francis; GOLIOT-LÉTÉ, Anne. Ensaio sobre a análise fílmica. Campinas: Papirus, 1994.

VIDA de inseto. Direção: John Lasseter, Andrew Stanton. Produção: D. A. Anderson, K. Reher. Estados Unidos: Walt Disney \& Pixar, 1997. 1 DVD (102 min).

Recebido para publicação em 06/08/2014 Revisado em 21/08/2014 Aceito em 12/09/2014 